\title{
Prevalência de más oclusões na primeira infância e sua relação com as formas de aleitamento e hábitos infantis
}

\author{
Carla Maria Melleiro Gimenez*, Antonio Bento Alves de Moraes***, \\ André Pinheiro Bertoz*, Francisco Antonio Bertoz**, Gláucia Bovi Ambrosano****
}

\begin{abstract}
Resumo
Objetivo: identificar a prevalência e os tipos de má oclusão encontrados em crianças dentro da faixa etária de 2 a 4 anos; e correlacionar a presença de más oclusões com a forma de aleitamento e com os hábitos bucais infantis. Metodologia: foram avaliadas por meio de exame clínico 226 crianças de 2 a 4 anos, sendo 100 delas inseridas no programa de prevenção do Centro de Pesquisa e Atendimento a Pacientes Especiais (Cepae) - FOP UNICAMP, e 126 pertencentes a creches municipais da cidade de Piracicaba. Foi também aplicado um questionário dirigido aos responsáveis a respeito dos hábitos infantis e formas de aleitamento, sendo os dados submetidos à análise estatística de Fischer $(\mathrm{p}<0,05)$. Resultados e Conclusões: observou-se alta prevalência de más oclusões (superior a 50\% da amostra avaliada) e verificouse uma correlação positiva entre a falta de amamentação natural e hábitos bucais inadequados em relação à presença de más oclusões na amostra analisada. A chupeta revelou-se a variável mais significativa na contribuição para a instalação de más oclusões.
\end{abstract}

Palavras-chave: Má oclusão. Aleitamento. Hábitos bucais.

\section{INTRODUÇÃO}

As más oclusões, desvios morfológicos de natureza biofísica do aparelho mastigatório, devido à sua alta prevalência, são consideradas um problema de saúde pública. Diversos autores têm considerado o padrão normal de oclusão quase uma exceção ${ }^{2,18,20}$. O estudo das más oclusões e de sua etiologia é de fundamental importância para o cirurgião-dentista que, por meio do diagnóstico precoce e de medidas preventivas, inclusive com a conscientização do paciente e/ou responsáveis, consegue impedir e/ou interceptar problemas de difícil solução em longo prazo $2,20,21,29$. Conscientizar significa lidar com o comportamento do paciente e da família por meio das informações individualizadas e de estratégias psicológicas de intervenção, destinadas à mudança de comportamentos e à manutenção dos padrões adequados de saúde bucal ${ }^{28}$.

A auto correção das más oclusões não ocorre,

* Mestre em Ortodontia na Faculdade de Odontologia de Araçatuba - UNESP.

** Professor Doutor do Departamento de Odontologia Infantil e Social da Faculdade de Odontologia de Araçatuba - UNESP.

*** Professor Doutor do Departamento de Odontologia Preventiva e Social da Faculdade de Odontologia de Piracicaba - UNICAMP.

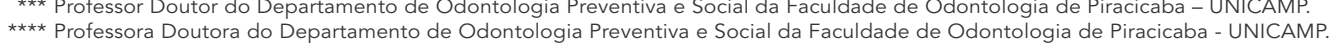


sendo que os desvios que se estabelecem na dentadura decídua perpetuam-se na dentadura mista, assim como na dentadura permanente. Esta observação respalda o consenso mundial de que a prevenção e a interceptação precoce se fazem necessárias, preferencialmente, nas dentaduras decídua e mista. Além disso, nas fases onde se conta com o crescimento do indivíduo e com o alto grau de remodelação, as respostas fisiológicas são mais favoráveis: a bioelasticidade óssea está presente contribuindo significantemente para o reequilíbrio do sistema estomatognático ${ }^{2,12}$.

O cirurgião-dentista, através de sua formação básica, deveria receber conhecimentos sobre a importância da prevenção e interceptação das más oclusões. Entretanto muitos dos pacientes encaminhados pelo clínico ou pelo odontopediatra chegam ao ortodontista na fase da dentadura permanente, quando a maioria dos problemas oclusais já se encontram instalados. Portanto a monitorização do estabelecimento das dentições e da oclusão deve ser realizada pelo cirurgião-dentista e pelo odontopediatra, com o propósito de garantir o desenvolvimento potencial de todas as estruturas pertencentes ao complexo bucomaxilofacial, possibilitando o desenvolvimento de suas funções normais.

A literatura ${ }^{17}$ mostra que a forma de aleitamento interfere no padrão de movimentação dos músculos mastigatórios, no correto estabelecimento da deglutição e da respiração, além de suprir as necessidades nutricionais e neurológicas da criança, sendo a sucção considerada a primeira fase da mastigação. A falta ou ausência do aleitamento natural correlaciona-se ao hipodesenvolvimento do complexo mastigatório, à instalação de respiração mista ou bucal, deglutição atípica e, conseqüentemente, ao desenvolvimento inadequado que conduz às más oclusões ${ }^{6,7,9,10}$.

Por outro lado, hábitos bucais infantis são também fatores que interagem no estabelecimento da oclusão. Os hábitos surgem, muitas vezes, pela necessidade neural de sucção, inerente à primeira etapa do desenvolvimento. Como a interposição de objetos ou a sucção não nutritiva exercem pressões e forças contínuas sobre as estruturas em formação, ocorre o estabelecimento de discrepâncias ou desvios. Com a maturidade óssea, estes desvios podem tomar dimensões alarmantes, que podem afetar, inclusive, a articulação temporomandibu$1 a^{7,26,30}$. Além disso, não se pode desconsiderar a importância do aleitamento natural no desenvolvimento psicológico da criança, sendo esta situação fundamental em relação às trocas afetivas e às experiências de contato social.

Tendo como objetivo geral a promoção de saúde, este trabalho pretende contribuir para o estudo da prevenção das más oclusões, no sentido de conscientizar os profissionais quanto à necessidade de controle das condições em que se processam o desenvolvimento das estruturas do sistema estomatognático durante a primeira infância.

\section{OBJETIVOS}

1) Identificar a prevalência de más oclusões em crianças dentro da faixa etária de 2 a 4 anos inseridas no programa de prevenção do Centro de Atendimento e Pesquisa a Pacientes Especiais (Cepae) - FOP UNICAMP e em crianças da mesma idade pertencentes às creches municipais da cidade de Piracicaba.

2) Identificar os tipos de más oclusões encontradas.

3) Relacionar as más oclusões com as formas de aleitamento e hábitos bucais.

4) Orientar os responsáveis pelas crianças, principalmente aquelas com predisposição ao desenvolvimento de más oclusões, sobre os cuidados necessários e os serviços disponíveis para a realização do tratamento preventivo.

\section{REVISÃO DA LITERATURA \\ Relação oclusal}

As relações oclusais na dentadura decídua e seu significado no desenvolvimento da dentadura permanente têm sido tema de discussão ao longo de 
várias décadas. Desde o início do século, observase que, se existe má oclusão na dentadura decídua, o mesmo poderá ocorrer na dentadura permanente, até mesmo em maior grau, segundo os estudos de Baume². Neste mesmo estudo, feito com 60 crianças, acompanhou-se a transição da dentadura decídua para a permanente e concluiu-se que as más oclusões encontradas na primeira dentadura se perpetuam na permanente, assim como o desenvolvimento e crescimento continuam seguindo o mesmo padrão. Tal fato é confirmado nos rela-

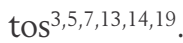

Foster e Grundy ${ }^{14}$, num estudo longitudinal, descreveu as características oclusais de crianças aos 5 anos e posteriormente aos 12 anos, constatando que o grau de trespasse vertical dos incisivos e o trespasse horizontal dos incisivos variaram muito pouco da decídua para a permanente. Observou também que as relações sagitais (relação terminal dos molares decíduos: degrau mesial, plano reto ou degrau distal) dos arcos dentários foram bastante estáveis, ou seja, as más oclusões identificadas na dentadura decídua persistiram na permanente.

Farsi e Salama ${ }^{13}$, observando 520 crianças sauditas, concluiu existir diferenças entre grupos etários, como a menor proporção de degrau distal em crianças de 5 anos comparadas às de 3 anos. $\mathrm{O}$ grau de trespasse vertical dos incisivos foi menor aos 5 anos, houve uma maior prevalência de trespasse horizontal dos incisivos no grupo de crianças mais velhas, mostrando a não ocorrência de uma "auto-correção" das más oclusões com o passar da idade.

Johannsdottir et al. ${ }^{19}$ mostrou a prevalência das diferentes más oclusões em 396 crianças de 6 anos de idade, relatando que $27 \%$ dos garotos e $31 \%$ das garotas apresentaram distoclusão (degrau distal), enquanto 6 e $5 \%$, respectivamente, mesioclusão (degrau mesial). Estes padrões permaneceram estáveis na permanente, notando-se que ocorreu uma maior incidência de más oclusões do tipo Classe I de Angle neste período.

Brin $^{5}$, através de modelos de gesso, estudou as relações oclusais de duas gerações de crianças, percebendo que, com o passar da idade, houve um decréscimo da prevalência de oclusão normal, acompanhado de um aumento na prevalência de más oclusões do tipo Classe I de Angle (a relação mesiodistal entre os primeiros molares é correta, mas há desarmonia entre o volume ósseo e dentario, provocando apinhamentos na região anterior), o que se encontra em concordância com os estudos de Johannsdosttir ${ }^{19}$.

Silva Filho et al. ${ }^{37}$, em estudo epidemiológico das más oclusões na dentadura decídua, constataram que apenas $26,74 \%$ das crianças entre 3 e 6 anos apresentavam características de oclusão normal. Os $73,26 \%$ da população estudada exibiram algum padrão de má oclusão, o que demonstrou que a freqüência da má oclusão na dentadura decídua é tão elevada quanto nos estágios subseqüentes de desenvolvimento da oclusão. Dentre as más oclusões, as seguintes entidades clínicas foram diagnosticadas, por ordem de prevalência: mordida aberta anterior $(27,97 \%)$, mordida cruzada posterior unilateral $(11,65 \%)$, mordida aberta anterior associada à mordida cruzada posterior $(6,99 \%)$, mordida cruzada posterior unilateral direita $(6,84 \%)$, mordida cruzada posterior unilateral esquerda $(4,81 \%)$, mordida cruzada anterior $(3,57 \%)$, perdas precoces de dentes decíduos $(2,82 \%)$, mordida cruzada posterior bilateral $(1,19 \%)$ e mordida cruzada total $(0,19 \%)$.

\section{Aleitamento}

Sabe-se que, além do desenvolvimento préestabelecido pelo código genético, a oclusão sofre influências extrínsecas que redirecionam ou provocam alterações indesejáveis. Neste processo de desenvolvimento, a sucção é considerada a primeira fase da mastigação, pois ambas envolvem os mesmos grupos musculares. Além disso, através dos movimentos de ordenha que são realizados quando do aleitamento natural (protrusão, retrusão, levantamento e abaixamento da mandíbula), ocorre desenvolvimento e tonificação dos múscu- 
los mastigatórios, dos ligamentos e da articulação temporomandibular (ATM), preparando-os para a chegada da dentição e, funcionalmente, para a mastigação ${ }^{6,7}$. A amamentação natural, portanto, exerce grande influência na fase do desenvolvimento da oclusão decídua, pois além de seus aspectos nutricionais, imunológicos e emocionais, desempenha também um importante papel funcional. Através dos movimentos de ordenha, observa-se a promoção de estímulos adequados para a satisfação do impulso neural de sucção, a garantia do sustento nutricional, condições favoráveis ao desenvolvimento craniofacial e dentário. Além disso, a amamentação natural previne más oclusões por hipodesenvolvimento, estabelecendo, assim, um padrão correto de respiração, postura e atividade muscular ${ }^{6,7,9,10}$.

Ao longo dos anos, vários autores ${ }^{1,10,11,24}$ têm se preocupado com a associação entre as formas de aleitamento e a instalação de hábitos bucais indesejáveis, pois a partir da incorporação destes hábitos percebe-se uma tendência para o desenvolvimento de más oclusões. Em 1926, no primeiro livro de Odontopediatria publicado, Jordon (apud MARTINS JR. ${ }^{24}$, 1987) abordou a importância do aleitamento materno no desenvolvimento do sistema estomatognático, ao descrever a possibilidade de instalação de futuras más oclusões em crianças que não tiveram o aleitamento natural.

Há controvérsias em relação ao tempo ideal de aleitamento suficiente para o desenvolvimento adequado das estruturas do sistema mastigatório, pois alguns autores sugerem que um período de seis a nove meses seria o recomendável ${ }^{17,25,31}$. Por outro lado, tem sido estudada a importância da amamentação quanto à prevenção de hábitos orais indesejáveis e, quando estes já se encontram instalados, o tipo e a freqüência suficientes para provocarem uma má oclusão $0^{9,12,33}$.

\section{Aleitamento e hábitos infantis}

Commeford ${ }^{9}$ demonstrou que $92 \%$ das crian- ças que receberam aleitamento no seio materno, como forma exclusiva de alimentação nos primeiros meses de vida, não apresentaram hábitos de sucção deletéricos.

Egovic e Ostric ${ }^{12}$ observaram que $58,8 \%$ das crianças examinadas em sua amostra, as quais foram amamentadas no seio por três meses ou mais, não eram usuárias de chupeta; enquanto $31 \%$ das crianças desta amostra, que foram alimentadas exclusivamente na mamadeira, tornaram-se usuárias de chupeta. Em relação às crianças que apresentaram o hábito de sucção digital, os resultados obtidos mostraram que $20,6 \%$ destas foram amamentadas de forma natural por 3 meses apenas e $13,1 \%$ foram alimentadas exclusivamente com mamadeira.

Paunio et al. ${ }^{33}$ estudaram a associação entre hábitos de sucção de dedo e chupeta com o aleitamento natural em 1.018 crianças de 3 anos de idade em Turku, Finlândia. Observou-se que, à medida que o tempo de aleitamento diminuía, aumentava o risco da utilização de chupeta até os 3 anos de idade, comparativamente às crianças que receberam aleitamento natural por 6 meses. Não foi possível estabelecer uma relação entre o aleitamento natural e a sucção digital, devido ao pequeno número de crianças com este hábito $(1,7 \%)$.

As teorias que tentam explicar esta tendência sugerem que bebês aleitados de forma natural executam intenso trabalho muscular ao sugar o seio materno, ficando a musculatura peribucal fatigada, o que faz com que a criança durma e não necessite de sucção de chupeta, dedos e objetos $^{38}$. Além disso, a saciedade das necessidades psico-afetivas pelo contato próximo através do aleitamento materno, sobrepõe-se à busca de objetos comumente utilizados para a satisfação oral: chupeta e dedo ${ }^{32}$.

Em 1977, Serra Negra et al. ${ }^{35}$, através de uma pesquisa com 357 crianças de 3 a 5 anos de idade constataram haver associação altamente significativa entre o aleitamento natural e a não instalação de hábitos bucais, pois $86,1 \%$ das crianças 
que não os apresentavam foram amamentadas por, no mínimo, 6 meses. Verificaram também que crianças aleitadas por mamadeira apresentavam o risco de desenvolver hábitos bucais quase dez vezes maior do que aquelas que nunca utilizaram esta forma de aleitamento. Houve uma forte associação entre estes hábitos e a ocorrência de más oclusões. A mordida aberta anterior, a mordida cruzada posterior e a sobressaliência, mostraram-se diretamente relacionadas à presença de hábitos bucais.

Verificou-se que quando crianças são alimentadas por mamadeira o trabalho da musculatura peribucal é minimizado, porque com um menor número de sucções a criança é saciada nutricionalmente. No entanto, o êxtase emocional não é atingido e assim a criança buscará substitutos como o dedo, chupeta e objetos para suprir esta necessidade ${ }^{6,7}$. A freqüência, duração e intensidade do hábito praticado podem ter como conseqüências deformidades nas relações dentoalveolares, desequilíbrio e disfunções nos músculos faciais, mau posicionamento dentário, mordida aberta e/ou cruzada, sobressaliência e giroversões dentárias. Os hábitos mais comuns são a sucção de chupeta e a sucção digital ${ }^{4,30,31,33}$.

\section{Hábito de sucção e má oclusão}

Biscaro et al. ${ }^{4}$, num levantamento epidemiológico de más oclusões em 891 escolares de 7 a 12 anos da cidade de Piracicaba, constataram a presença de más oclusões por meio de exame clínico, análise da oclusão e pesquisa de suas possíveis etiologias. Verificou-se a relação incisiva, relação de caninos, relação molar, chave de oclusão, mordida cruzada, mordida aberta e presença de diastema medial. Após a coleta de dados, concluiu-se que a porcentagem de desvios da oclusão foi de $97,7 \%$. Esta significativa quantidade de más oclusões pode ser atribuída aos hábitos orais indesejáveis, inerentes à faixa etária examinada.

Navarro e Chelott ${ }^{30}$ objetivaram, em seu estudo com 1.064 escolares de 5 a 11 anos, determinar as manifestações clínicas e a freqüência de hábi- tos bucais. Os resultados mostraram que 20\% das crianças apresentavam hábitos e que a sucção digital foi o hábito de maior incidência. A partir dos sete anos os hábitos de projeção de língua, sucção digital e respiração bucal diminuíram consideravelmente.

Leite et $\mathrm{al}^{20}$ aplicaram um questionário aos pais ou responsáveis por 100 crianças, entre 2 e 11 anos, de ambos os gêneros, relacionado ao tipo de aleitamento e à presença de hábitos de sucção não nutritivos. Os autores observaram a amamentação materna exclusiva em $24 \%$ das crianças, a associação entre o uso da amamentação mista ou artificial e o uso de chupeta (além de outros hábitos de sucção), bem como o relato de problemas respiratórios. Tornou-se clara, no artigo, a ênfase dada à importância do aleitamento natural, especialmente nos 6 primeiros meses de vida, como forma de prevenção contra futuros problemas de ordem sistêmica e ordem bucal, ou seja, as más oclusões.

Em 1991, Mongullhott et al. ${ }^{27}$ pesquisaram os tipos de oclusão em 334 crianças portadoras de hábitos de sucção digital, procurando correlacionar este hábito com a má oclusão resultante. Constatou-se que 50,9\% da amostra apresentavam má oclusão Classe I de Angle; 17,96\% possuem a má oclusão Classe II e 9,28\% má oclusão Classe III. Não foram encontradas diferenças significantes entre os gêneros e pode-se afirmar que prevalece a oclusão Classe I sobre a Classe II, e esta sobre a Classe III, sendo as diferenças entre elas estatisticamente significantes a um nível de 5\%.

Maraccini et al. ${ }^{23}$, num estudo com 19 crianças entre 6 e 10 anos portadoras do hábito de deglutição atípica, notaram uma correlação com mordida aberta, atresia maxilar, mordida cruzada posterior uni e bilateral. Afirmaram ainda que a língua, por sua potência, é capaz de alterar a posição dentária e das estruturas adjacentes, agindo como fator primário no desenvolvimento dentário e das bases ósseas da face, tendo uma atividade reguladora determinante da forma final dos arcos dentários. 
Silva Filho et al. ${ }^{38}$ realizaram um estudo epidemiológico com o propósito de verificar a prevalência dos hábitos bucais de sucção na dentadura decídua e os diferentes tipos de más oclusões deles decorrentes. Os hábitos bucais de sucção estiveram presentes em $48,86 \%$ das crianças, sendo mais prevalentes no gênero feminino $(54,37 \%)$. As crianças demonstraram menor dependência dos hábitos de sucção com o aumento da idade. Com relação às formas que os hábitos se exprimem, as mais freqüentes foram: mamadeiras $(29,96 \%)$ e chupeta $(28,95 \%)$, seguidas pela associação de hábitos $(20,68 \%)$, dedo $(9,72 \%)$ e interposição de lábio $(0,89 \%)$. Dentre as más oclusões relacionadas aos hábitos, a mais prevalente foi a mordida aberta anterior $(50,76 \%)$, seguida pela mordida cruzada posterior $(18,88 \%)$ e pela associação entre mordida aberta anterior e mordida cruzada posterior $(10,35 \%)$. Cerca de $20 \%$ das crianças com hábitos bucais de sucção não exibiram más oclusões com etiologia vinculada à presença deles. Não foi constatado vínculo etiológico entre hábitos bucais de sucção e relação dentária de Classe II.

\section{A respiração bucal ou mista}

Fujiki e Rossato ${ }^{15}$, numa ampla revisão da literatura, estudaram a correlação entre o padrão respiratório e a morfologia craniofacial, com o objetivo de elucidar a estreita relação entre a função naso-respiratória e os eventos de crescimento e desenvolvimento dentocraniofacial, demonstrando a grande influência dos fatores ambientais sobre o padrão genético. Os autores descrevem, ainda, as características clínicas, oclusais e cefalométricas dos portadores da síndrome da face longa. Ressaltaram, também, a necessidade de maior número de pesquisas discutindo a influência desta temática no desenvolvimento das más oclusões e lembrando o ato respiratório como sendo um fator do desenvolvimento, mas que não deve ser considerado isoladamente.

Lusvarghi $^{21}$ estudou a síndrome do respirador bucal, correlacionando-a a vários desvios da normalidade e más oclusões. Numa revisão da literatura, o autor descreveu as características do respirador bucal, as conseqüências desse padrão respiratório no desenvolvimento dentocraniofacial, evidenciando a importância do diagnóstico precoce, que pode ser realizado pelo cirurgiãodentista, e a necessidade da interação multidisciplinar entre os profissionais das áreas médica e odontológica para a obtenção de um melhor resultado para o paciente.

\section{MATERIAL E MÉTODOS}

Esta pesquisa analisou 100 crianças inseridas no Programa de Prevenção do Cepae (Centro de Pesquisa e Atendimento de Pacientes Especiais) e 126 crianças das creches municipais da cidade de Piracicaba, de diferentes classes sociais, de ambos os gêneros, na faixa etária de 2 a 4 anos, com a dentadura decídua completa. O critério para exclusão seria a presença de amplas destruições coronárias, perdas precoces de elementos dentários, anomalias e patologias do tipo más formações dentofaciais, o que poderia alterar as características dos arcos dentários decíduos, como perdas de espaços, desvios, retardo no desenvolvimento, predisposição a problemas oclusais. O gênero e classe social das crianças não seriam fatores de exclusão, uma vez que na literatura não há relatos de interferência desses fatores no resultado dos estudos referentes ao desenvolvimento da oclusão. As crianças participantes não foram identificadas e a coleta de dados foi continuamente controlada pelos pesquisadores responsáveis. Os sujeitos não foram submetidos a nenhum risco de dano físico ou moral durante os procedimentos de coleta de dados necessários à realização do trabalho, uma vez que foram utilizados procedimentos clínicos convencionais e uma forma de registro sistemática e regular.

Os pais ou responsáveis pelas crianças foram esclarecidos e consultados sobre a pesquisa pelos profissionais responsáveis e, se permitida a participação das mesmas, assinaram um "Termo de 
Consentimento Livre e Esclarecido" de acordo com as exigências éticas da pesquisa em humanos (Resolução 196/96 do Conselho Nacional de Saúde/MS). Quanto ao ressarcimento de gastos, os responsáveis pela criança receberam vales transporte para comparecerem ao Cepae, no caso das crianças inseridas em seu programa preventivo. De acordo com o planejamento deste trabalho, os dados foram coletados nos dias de atendimento regular do Cepae, e no caso das crianças das creches, o pesquisador dirigiu-se até o local para o exame das mesmas.

Foi realizado um exame clínico detalhado em relação às características oclusais de cada criança. Para tanto se utilizou espelho clínico e luz artificial (refletor do equipo odontológico), com a criança reclinada, em relação cêntrica, para a observação. Foram registradas as seguintes características oclusais:

- Mordida aberta: através da ausência de contato dentário na região anterior e/ou lateral, ou ainda trespasse vertical negativo.

- Mordida cruzada e cruzamentos dentários isolados: pelo contato invertido entre as cúspides dentárias nas fossas oclusais no caso de dentes posteriores e pela interposição dos dentes anteriores para posição contrária.

- Sobremordida: através da magnitude do trespasse vertical.

- Sobressaliência: através da graduação do trespasse horizontal.

Foi preenchido um questionário (Quadro 1) com perguntas direcionadas aos responsáveis em relação à:

- Forma de aleitamento da criança. No caso de mamadeiras, a freqüência, o tipo de bico e a idade em que começou o uso da mamadeira.

- Respiração da criança, ocorrência de rinites, adenopatias, ronco ou baba noturna.

- Presença e freqüência dos hábitos como chupar dedo, chupetas, morder a mucosa, chupar objetos, roer unhas ou ranger os dentes.

- Observações das mães.

Neste questionário, as informações pretendiam buscar a identificação dos fatores etiológicos das más oclusões, hábitos orais indesejáveis, tipo e freqüência de aleitamento, presença de respiração bucal e outras observações dignas de registro.

Os indicadores de más oclusões foram observados em relação cêntrica, para que houvesse contato dentário sempre na mesma posição, padronizando-se o exame para todas as crianças. As crianças que exibiram predisposição ou os indicadores de más oclusões já instalados foram orientadas quanto à necessidade de tratamento ortodôntico preventivo e encaminhadas aos serviços e profissionais competentes para a interceptação destes problemas.

Os dados clínicos e as informações obtidas por meio dos questionários foram analisados e submetidos ao teste estatístico de Fischer $(\mathrm{p}<0,05)$.

\section{RESULTADOS}

Este trabalho contou com uma amostra de 226 crianças, sendo 100 delas inseridas no programa de prevenção do Cepae e 126 pertencentes às creches municipais de Piracicaba. Os dados estatisticamente significantes segundo o teste de Fischer $(p<0,05)$ foram organizados nos gráficos 1 a 13.

Observa-se que houve uma considerável percentagem de más oclusões na amostra analisada. Vale notar que não houve diferença estatisticamente significante $(p<0,05)$ entre a distribuição das más oclusões no Cepae e nas creches.

Observa-se que a maioria das crianças, tanto no Cepae quanto nas creches, amamentaram por um período inferior ou até os seis meses de idade, não ocorrendo diferença significativa estatisticamente entre o Cepae e a creche.

Pode-se perceber que grande parte das crianças dentro da faixa etária analisada é portadora do hábito de sucção de chupeta, não havendo diferença estatística entre os dados encontrados no Cepae ou nas creches.

Constatou-se que apenas uma pequena percentagem da amostra analisada apresentou o hábito de sucção digital, não havendo diferença es- 
QUESTIONÁRIO

1) Aleitamento

a) A criança mamou no peito até quantos meses?

b) Caso o aleitamento seja artificial, qual o utensílio usado para a criança receber o leite?

( ) copo ( ) canudo ( ) mamadeira

c) Se mamadeira: qual o tipo de bico? ( ) nuil ( ) lillo ( ) onod ( ) outros

2) Freqüência do aleitamento por mamadeira :__ $x$ ao dia __ $x$ por noite

a) Qual a idade que começou com a mamadeira?

3) Tipo de respiração ( ) bucal ( ) nasal ( ) mista

a) A criança apresenta rinite alérgica, adenopatias, ronco ou baba noturna?

4) Chupa chupeta? ( ) sim ( ) não

( ) para dormir/ à noite.

( ) durante várias horas do dia.

5) Qual o tipo de chupeta?

6) Chupa dedo? ( ) sim ( ) não ( ) às vezes ( ) o dia todo

6) Tem algum hábito?

( ) morder mucosa ( ) chupar objetos ( ) roer unhas

( ) bruxismo (ranger os dentes)

7) Tem alguma outra observação a relatar?

\section{EXAME CLÍNICO}

8) Más oclusões

( ) mordida aberta ( ) mordida cruzada posterior ( ) unilateral ( ) bilateral

( ) mordida cruzada anterior ( ) sobremordida ( ) sobressaliência

( ) deglutição atípica

9) A criança possui vedamento labial? ( ) sim ( ) não

Quadro 1 - Questionário utilizado na presente pesquisa.

tatisticamente significante entre os dados obtidos entre as crianças do Cepae e das creches.

Observou-se que o tempo de amamentação natural influenciou significantemente na prevenção de más oclusões, visto que crianças amamentadas por períodos maiores ou iguais a seis meses apresentaram menor ocorrência de más oclusões.

Pode-se notar que o hábito de sucção de chupeta esteve altamente relacionado com a instalação de más oclusões ( $\mathrm{p}=0,00000007)$ em crianças da amostra analisada.

Observou-se que a chupeta não esteve diretamente correlacionada com o padrão de respiração bucal, pois a maioria das crianças que era portadora do hábito de sucção de chupeta apresentou respiração mista ou nasal.
Nota-se que a freqüência do hábito de chupeta interfere na ocorrência de más oclusões, pois a maior parte das crianças que apresentaram más oclusões chupavam chupeta várias horas por dia ou tanto de dia como de noite (nos dois períodos do dia).

Notou-se uma maior ocorrência de más oclusões frente à presença de hábitos bucais.

O hábito de sucção digital foi significantemente correlacionado à presença de más oclusões.

A presença de problemas sistêmicos (rinites, alergias, problemas respiratórios) esteve significantemente associada à alteração do padrão respiratório normal (nasal), com forte correlação com a respiração bucal e mista.

Notou-se que a maioria das crianças não apresenta um vedamento labial adequado, principal- 


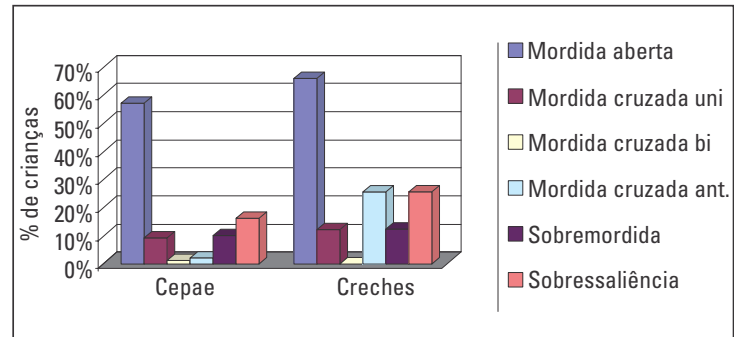

GRÁFICO 1 - Distribuição percentual das más oclusões observadas na amostra analisada.

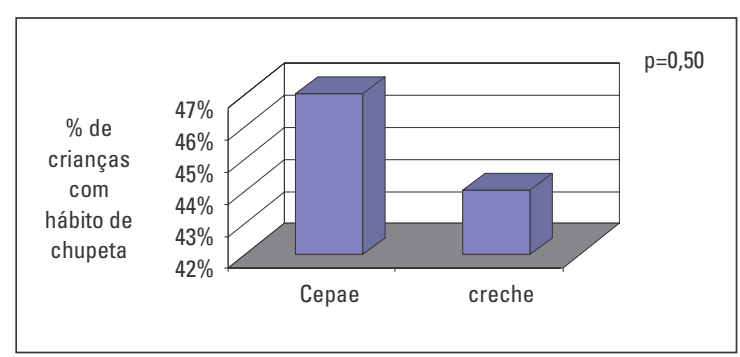

GRÁFICO 3 - Porcentagem de crianças com hábito de sucção de chupetas.

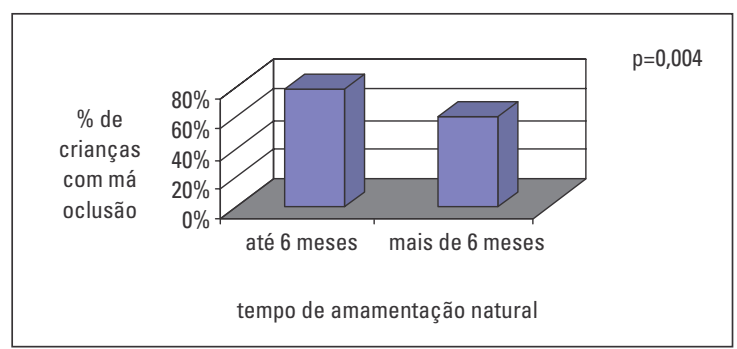

GRÁFICO 5 - Porcentagem de crianças com más oclusões em função do tempo de amamentação natural.

mente as crianças que apresentam respiração bucal e mista.

Pode-se perceber uma maior ocorrência de más oclusões em crianças que não apresentam adequado vedamento labial.

Não apresentaram correlação estatisticamente significante, segundo o teste de Fischer $(p<0,05)$ :

- A freqüência do aleitamento por mamadeira em relação às más oclusões $(\mathrm{p}=0,98)$.

- O tipo de respiração em relação à presença

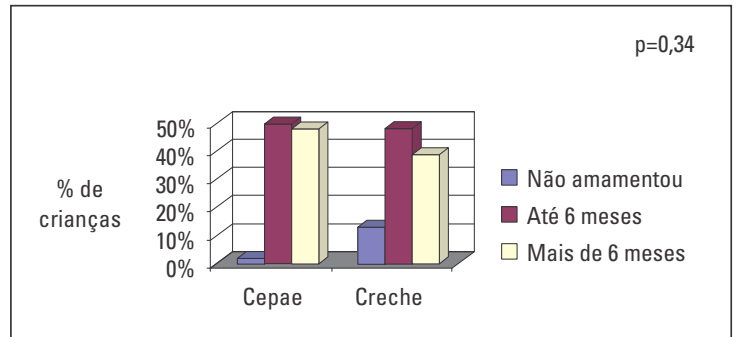

GRÁFICO 2 - Distribuição percentual da amostra analisada segundo o tempo de amamentação.

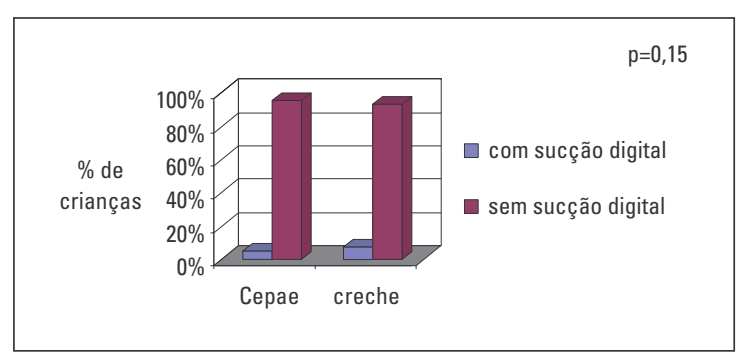

GRÁFICO 4 - Porcentagem de crianças com hábito de sucção digital.

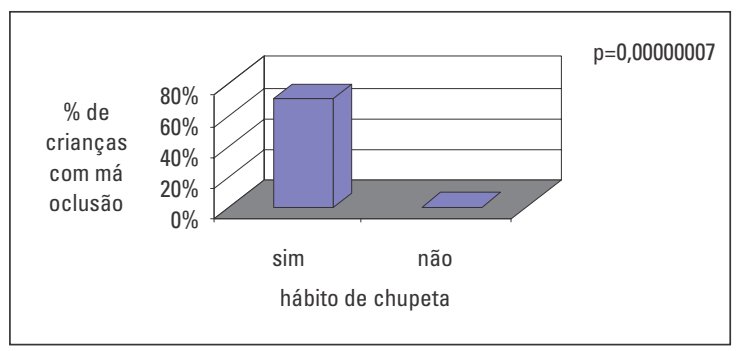

GRÁFICO 6 - Porcentagem de crianças com más oclusões em função do hábito de sucção de chupeta.

de más oclusões $(\mathrm{p}=0,98)$.

- A influência da mamadeira no tipo de padrão respiratório (total $\mathrm{p}=0,75$ ).

- Correlação do uso da mamadeira com a presença de problemas sistêmicos $(\mathrm{p}=0,19)$.

- Presença de problemas sistêmicos (adenopatias, alergias, bronquites, patologias respiratórias) e o hábito de sucção de chupeta $(\mathrm{p}=1)$.

- O hábito de sucção digital em relação às más oclusões $(p=0,41)$, tipo de respiração $(p=0,67)$, 


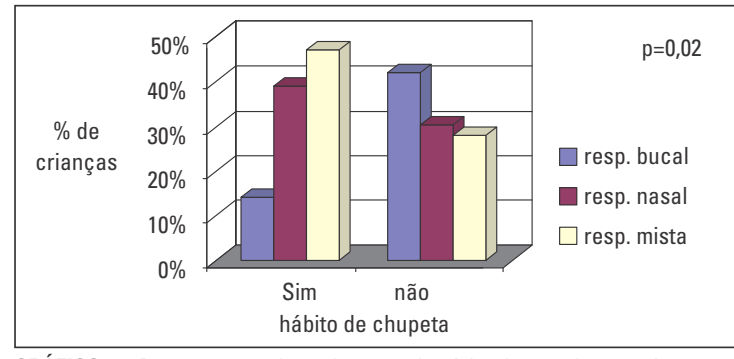

GRÁFICO 7 - Porcentagem do padrão respiratório observado em relação a hábito de sucção de chupeta.

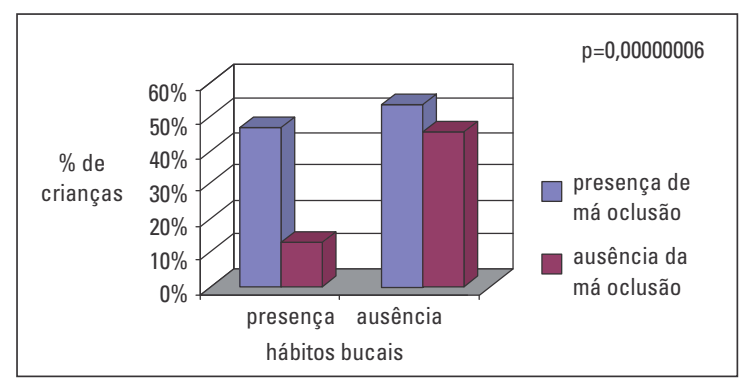

GRÁFICO 9 - Porcentagem de crianças com más oclusões em função da presença de hábitos bucais.

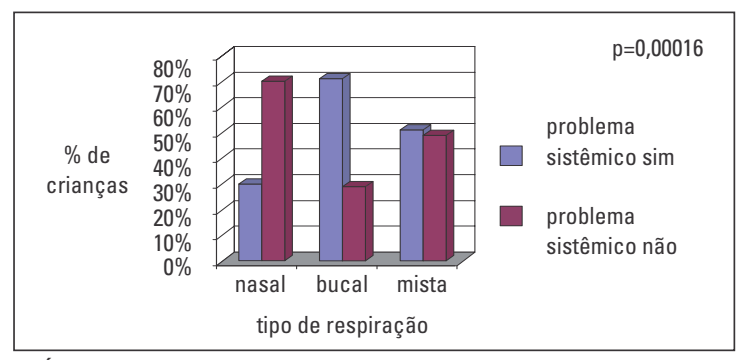

GRÁFICO 11 - Relação entre problema sistêmico e o tipo de respiração apresentada.

problemas sistêmicos $(\mathrm{p}=1)$ e freqüência do hábito com a presença de más oclusões $(\mathrm{p}=1)$. Sugere-se que a ocorrência deste evento possa ser explicada devido ao tamanho reduzido da amostra de crianças que apresentaram este hábito.

- A presença de vedamento labial em relação ao tempo de amamentação natural $(\mathrm{p}=0,06)$.

\section{DISCUSSÃO}

A significativa presença de más oclusões na

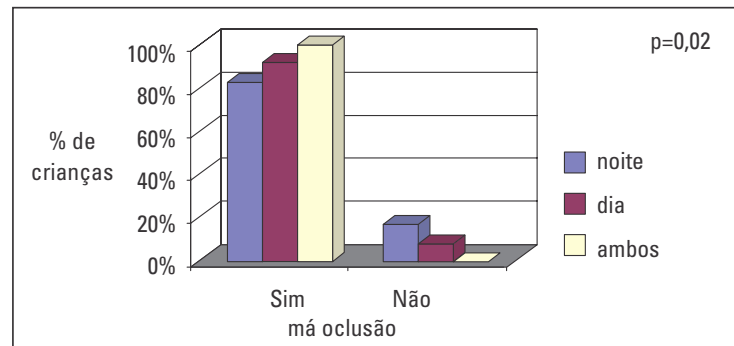

GRÁFICO 8 - Porcentagem de crianças com más oclusões de acordo com os períodos de sucção de chupeta.

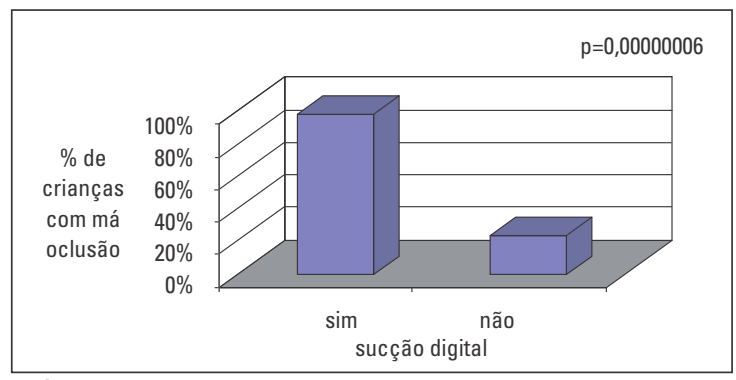

GRÁFICO 10 - Relação entre a presença de más oclusões e o hábito de sucção digital.

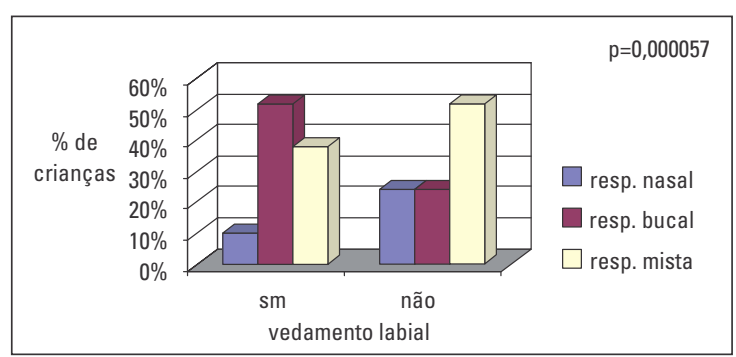

GRÁFICO 12 - Distribuição percentual da presença de vedamento labial em relação ao padrão de respiração.

amostra analisada (Gráf. 1), tanto isoladamente (Cepae e creches) quanto no conjunto, evidencia a face alarmante do problema de falta de medidas preventivas (incluindo o incentivo à amamentação natural) e a necessidade de interceptação destas más oclusões, o que está de acordo com os achados da literatura consultada $a^{4,19,23}$.

A maior parte das crianças, tanto do Cepae quanto das creches municipais, foi amamentada por um tempo inferior a 6 meses de vida (Gráf. 2). 


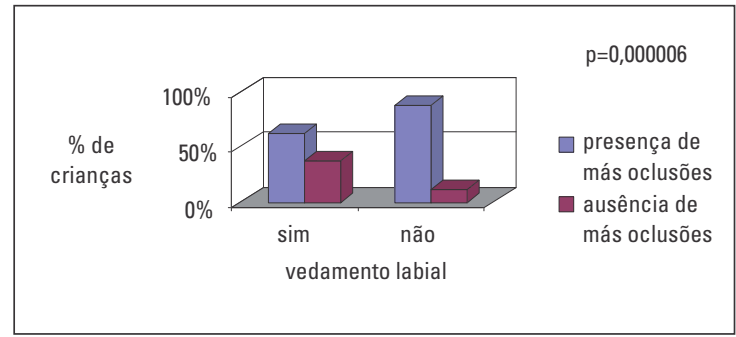

GRÁFICO 13 - Distribuição percentual de crianças com más oclusões em relação à ausência de vedamento labial.

Por outro lado, observa-se que as más oclusões foram menos freqüentes em crianças que tiveram aleitamento natural por mais de 6 meses. Provavelmente devido à falta de orientação às mães e gestantes em relação aos benefícios da amamentação natural, a maioria dessas crianças foi amamentada de maneira artificial precocemente. Além disso, a grande pressão dos fatores culturais e familiares compete fortemente com as orientações recebidas sobre saúde bucal, tornando as mães pouco sensíveis às recomendações do dentista. Esse fato foi relacionado à presença de más oclusões nas crianças das creches municipais, como relatam Carvalho e Serra $\mathrm{Negra}^{35}$ (Gráf. 5). Os resultados fortalecem as afirmações de Commeford e Ostric ${ }^{9}$, Egovic $^{12} \mathrm{e}$ Paunio et al. ${ }^{33}$, quanto à relevância da amamentação natural e da prevenção das más oclusões.

Embora a expectativa fosse encontrar más oclusões em associação significante com a freqüência de sucção de mamadeira, esta correlação não foi confirmada. A simples presença do aleitamento artificial em um único momento do dia já foi suficiente para a observação de más oclusões, principalmente a mordida aberta anterior, em concordância com a literatura ${ }^{7}$. Supõe-se que este evento tenha sido decorrente do seguinte fato: crianças aleitadas de maneira artificial também eram portadoras do hábito de sucção de chupeta.

Não houve correlação estatisticamente significante entre o uso da mamadeira com o padrão respiratório e a presença de problemas sistêmicos. Da mesma forma, o padrão respiratório também não apresentou correlação significante com a presença de más oclusões, o que se contrapõe aos relatos de Fujiki ${ }^{15}$ e Lusvarghi ${ }^{21}$. Talvez esta divergência seja devida ao tamanho da amostra analisada, ou pela grande quantidade de crianças (mesmo as respiradoras nasais) que apresentaram algum tipo de má oclusão. No entanto, o padrão respiratório foi positivamente relacionado com a presença de problemas sistêmicos, de acordo com os dados da literatura médica e odontológica ${ }^{6,7,24}$ (Gráf. 11).

O hábito de sucção de chupeta foi o mais freqüente, estando presente em $50 \%$ das crianças examinadas (Gráf. 3). Por sua altíssima correlação com a presença de más oclusões (Gráf. 9) e com o desvio no padrão respiratório normal (Gráf. 7), sugere-se que seja considerado como um dos fatores principais para o desencadeamento de más oclusões na faixa etária estudada. Não foi observada uma relação estatisticamente significante entre o uso da chupeta e a presença de problemas sistêmicos. Várias crianças que não possuíam problemas sistêmicos apresentavam hábito de sução de chupeta, o que poderia ser uma explicação para este fato.

A freqüência da sucção de chupeta no total da amostra foi estatisticamente significativa (maior número de crianças) quanto à presença de más oclusões (Gráf. 9), embora isoladamente nos dados obtidos no Cepae ou nas creches (Gráf. 3), não tenha apresentado suporte estatístico (por serem amostras relativamente reduzidas).

Outros hábitos bucais apresentados pelas crianças da amostra analisada, como a interposição ou sucção de objetos, bruxismo e onicofagia mostraram-se significantes estatisticamente em relação à presença de más oclusões (Gráf. 9), confirmando as hipóteses de Hanna ${ }^{17}$, Meyers ${ }^{25}$ e Ogard ${ }^{31}$, entre outros autores ${ }^{19,35,36,37}$.

Assim como Paunio ${ }^{33}$ que encontrou apenas $1,7 \%$ de portadores de sucção digital, uma reduzida parcela da amostra analisada neste trabalho apresentou este hábito (Gráf. 4), o que fez com que não houvesse correlação estatisticamente significante entre a presença de má oclusão, tipo de 
respiração, presença de problemas sistêmicos ou freqüência de hábitos em relação à má oclusão. Estes dados opõem-se aos de Navarro e Chellot$\mathrm{ti}^{30}$, que mostram a sucção digital como um hábito preponderante nas amostras estudadas.

A má oclusão resultante dos hábitos de sucção é semelhante, independentemente de chupeta ou dedo, com alterações na relação inter-arcos nos três sentidos de espaço. Portanto, a sucção digital ou de chupeta apresentam a mesma importância do ponto de vista de etiologia de instalação de más oclusões.

Em relação à presença de vedamento labial, houve correlação estatisticamente significante com a presença de más oclusões (Gráf. 13) e com o padrão respiratório (Gráf. 12) ) $^{6,715,21}$, evidenciando a interferência de hábitos ou tendências posturais e o tipo de respiração no desenvolvimento dentocraniofacial, mais uma vez confirmando a teoria da matriz funcional de $\mathrm{Moss}^{29}$. O vedamento labial não esteve relacionado de maneira estatisticamente significante com o tempo de amamentação.

É importante comentar que a ausência de selamento labial pode estar relacionada a problemas estruturais esqueléticos nos sentidos vertical (face longa) e sagital (deficiências mandibulares), além da hipotonicidade muscular que acompanha os hábitos infantis de sucção. Não necessariamente a ausência de selamento labial evoca o quadro de respiração bucal, mas podendo ser conseqüência de obstrução das vias aéreas. Essa diversidade de fatores explica a ausência de correlação entre tempo de amamentação e vedamento labial, o que dificulta a completa compreensão da ausência de selamento labial e o padrão respiratório. Na literatura, assim como na presente pesquisa, o diagnóstico do padrão respiratório tem sido subjetivo e não instrumental.

Observou-se que várias mães recusaram-se a amamentar os seus bebês. Segundo Moraes ${ }^{28}$, um modelo psicológico para a implementação de mudanças de comportamento de mães indica que estas não estão no mesmo estado de prontidão para alterar práticas de cuidado, para prevenir problemas bucais das crianças que cuidam. Prochaska e Diclemente ${ }^{34}$ apresentaram um modelo que já provou sua relevância para outros comportamentos de saúde, como realizar exercícios, perder peso e tomar decisões relacionadas a exames preventivos. O modelo propõe uma seqüência de estágios ao longo de um período contínuo que se inicia com a pré-contemplação (não pensar em atingir um comportamento de saúde alvo), seguida da comtemplação (pensar a respeito mas não ter nenhum plano definido para agir), a preparação (planejar a ação), a ação (início de um comportamento novo) e a manutenção (manter a ocorrência de um comportamento novo). As mudanças de um estágio para o outro podem ser avaliadas comparando-se a força dos aspectos positivos percebidos do novo comportamento (prós) com os aspectos negativos percebidos (contras).

O modelo de Prochaska sugere, ainda, que um ponto chave é aumentar a percepção e a sensibilidade do indivíduo. Ao mesmo tempo, a apresentação de dicas para a ação, para aqueles com baixa motivação, pode ativar o processo de mudanças.

\section{CONCLUSÕES}

Os resultados do presente trabalho nos permitem concluir que:

- O índice de más oclusões é alto em crianças na faixa etária avaliada.

- Existe uma correlação positiva entre falta de amamentação natural, hábitos bucais inadequados em relação à presença de más oclusões na população estudada.

- A chupeta revelou-se a variável mais significativa no desencadeamento de más oclusões em crianças de 24 a 58 meses. 


\title{
First childhood malocclusion's prevalence and its relation with breast feeding and oral habits
}

\begin{abstract}
Objective: to identify the prevalence and the different types of malocclusions in children, with ages from 2 to 4 years, correlationing this findings with the feeding methods and oral habits. Methodology: 226 children ware evaluated through the clinical oral examination; being 100 children that were participating in the early dental caries prevention program of the Research and Dental Treatment Center for Special Pacients (Cepae) of the State University of Campinas Dental School, 126 children belonged to the City Hall day-care services of Piracicaba. A questionnaire was applied to children's parents in relation to feeding methods and oral habits. The data was submitting to Fischer's statistical analyses $(p<0.05)$. Results and Conclusions: it was find high prevalence of malocclusions (plus than $50 \%$ of the analyzed sample), positives correlations between the absence of breast feeding, the presence of deleterious oral habits, when compared with the presence of malocclusions in the analyzed sample. The suction oral habit was the most important variable in the contribution to malocclusion's installation.
\end{abstract}

Key words: Malocclusion. Oral habits. Breast feeding.

\section{REFERÊNCIAS}

1. ALMEIDA, M. F. Nutrição e cuidados com o recém-nascido. Pediatr. mod., São Paulo, v. 28, n. 1, p. 67-85, 1992

2. BAUME, L. J. Phisiological tooth migration and its significance for the developmentof oclusion: I. The biogenetic course of the deciduous dentition. J. Dent. Res. Alexandria, v. 12 p. $123-130,1950$

3. BELANGER, G. K. The rationale and indications for equilibration in the primary dentition. Quintessence Int., Berlin, v. 23, no. 3, P. 169-174, 1992

4. BISCARO, S. L. et al. Avaliação de má oclusão em escolares de Piracicaba na faixa etária de 7-12 anos. Rev. Odontopediatr. São Paulo, v. 3, n. 3, p. 145-153, 1994.

5. BRIN, l. et al. Does exist a secular trend in the distribution of oclusal patterns? Angle Orthod., Appleton, v. 68, no. 1, p. 81-84, 1998.

6. CARVALHO, G. D. A amamentação sob a visão funcional clínica da Odontologia. Rev. Secr. Saúde, Brasília/DF, v. 2, n. 10, p. $12-13,1995$

7. CARVALHO, G. D. Amamentação é prevenção das alterações funcionais e estruturais do sistema estomatognático. Odontologia Ensino e Pesquisa, Cruzeiro, v. 2, n. 1, p. 39-48, 1998.

8. BELANGER, G. K. The rationale and indications for equilibration in the primary dentition. Quintessence Int., Berlin, v. 23 no. 3, p. 169-174, 1992

9. COMMEFORD M. Sucking habits in the breast fed versus no breast fed children. J. Res. Orofac. Muscle Imbal., [s. I.], v. 88 no. 2, p.18-19, 1977

10. COSTA, M. C. O. et al. Aleitamento materno: causas de desmame e justificativas para amamentar. J. Pediatr., Rio de Janeiro v. 69, n. 3, p. 177-178, 1993.

11. CRESPIN, J. Alimentação da criança. In: MURAHOVSCHI, J. Pediatria: diagnóstico e tratamento. São Paulo: Sarvier, 1979. cap. 9, p. 11-15.

12. EGOVIC, M.; OSTRIC, L. The effects of feeding methods on the growth of the jaws in infants. J. Dent. Child., Fulton, v. 58, no. 3, p. 253-255, 1991.

13. FARSI, N. M.: SALAMA, F. S. Characteristics of primary dentition oclusion in a group of Saudi children. Int. J. Paediatr. Dent., Oxford, v. 6, no. 4, p. 253-259, 1996.

14. FOSTER, T. D.; GRUNDY, M. C. Occlusal changes from primary to permanent dentitions. Br. J. Orthod., Oxford, v. 13, no. 4 p.187-193, 1986.

15. FUJIKI, P. D. T.; ROSSATO, C. Influência da hipertrofia adenoideana no crescimento e desenvolvimento craniodentofacial. Ortodontia, São Paulo, v. 32, n. 1, p. 70-79, 1999

16. GOMES, M. L. A influência da alimentação civilizada na deteriorização do sistema estomatognático. JBO: J. Bras. Ortod. Ortop. Facial, Curitiba, v. 2, n. 10, p. 65-74, 1997.

17. HANNA, J. C. Breast feeding versus bottle feeding in relation to oral habits. J. Dent. Child., Fulton, v. 34, no. 1, p. 243-249, 1967.

18. INFANTE, P. F. An epidemiologic study of deciduous molar relations in preschool children. J. Dent. Res., Alexandria, v. 54 no. 4, p. 723-727, 1975

19. JOHANNSDOTTIR, B. et al. Prevalence of malocclusion in 6-years-old Iceland children. Acta Odontol. Scand., Oslo, v. 55 , no. 6, p. 398-402, 1997

20. LEITE, I. S. G. et al. Associação entre aleitamento materno e hábitos de sucção não nutritivos. Rev. Assoc. Paul. Cirur. Dent., Santo Amaro, v. 53, n. 2, p. 151-156, 1999.

21. LUSVARGHI, L. Identificando o respirador bucal. Rev. Assoc. Paul. Cirur. Dent., Santo Amaro, v. 53, n. 4, p. 265-274, 1999

22. MCNAMARA, J. A. The independent functions of the two heads of the lateral pterigoid muscle. Am. J. Anat. New York, v. 138 , p. $197-200,1973$

23. MARACCINI, V. et al. Deglutição atípica com pressão lingual na região geniana. Rev. Goiana Ortod., Goiana, v. 3, n. 2, p. 16-21, 1997.

24. MARTINS JR, J. Como e porque amamentar. 2. ed. São Paulo: Sarvier, 1987

25. MEYERS, A.; HERTZBERG, J. Bottle feeding and maloclusion: is there a association? Am. J. Orthod. Dentofacial Orthop. St. Louis, v. 93, no. 2, p. 149-152,1988.

26. MODESTO, A.; AZEVEDO, G. T. Hábito de sucção de polegar: como descontinuá-lo? Rev. Odontopediatr., São Paulo, v. 5, n. 2, p. $41-48,1997$

27. MONGULLHOTT, L. M. J. et al. Maloclusões em portadores do hábito de sucção. Rev. Goiana Ortod., Goiana, v. 39, n. 4, p. 298-300, 1991.

28. MORAES, A. B. A. Integração entre pesquisa e serviço de saúde. Cad. Psicol., Belo Horizonte, n. 1, p. 13-21, 1996. 
29. MOSS, M. L. Functional analysis of human mandibular growth. J. Prosthet. Dent., St. Louis, v. 1, p. 1149-1156, 1960.

30. NAVARRO, N. P.; CHELOTTI, A. Manifestações clínicas e freqüência de hábitos deformantes em crianças de 5-11 anos do município de Melena do Sur-Havana. Rev. Odontopediatr. São Paulo, v. 5, n. 4, p. 155-160, 1997.

31. OGAARD, B. et al. The effect of sucking habits, cohort, Sex, intercanine arch widths and breast bottle feeding on posterio crossbite in Norwegian and Swedish 3 years old children. Am. J. Dentofacial. Orthop., St. Louis, .v. 106, no. 2, p. 106- 161, 1994.

32. PASTOR, I.; MONTANA, K. Amamentação natural no desenvolvimento do sistema estomatognático. Rev. Odontopediat. São Paulo, v. 3, n. 4, p. 185-191, 1994.

33. PAUNIO, P. et al. The Finnish family competence study: the effect of living conditions on sucking habits in 3 years old children and dental occlusion. Acta Odontol. Scand., Oslo, v. 51, no.1, p. 23-29, 1993

34. PROCHASKA, J. O.; DICLEMENTI, C. C. Toward a comprehen- sive model of change. In: MILLER, W. R.; HEATHER, M. (Ed.). Treating addictive behaviors: process of change. 2 nd ed. New York: Plenum, 1986. p. 175-203.

35. SERRA NEGRA, J. M. C. et al. Estudo da associação entre aleitamento, hábitos bucais e maloclusões. Rev. Odontol. Univ., São Paulo, v. 11, n. 2, p. 79-86, 1997

36. SILVA FILHO, O. G. et al. Hábitos de sucção: elementos possíveis de intervenção Estomatol. Cult., Bauru, v.16, n. 4, p. 61-71, 1986.

37. SILVA FILHO, O. G. et al. Epidemiologia da má oclusão na dentadura decídua. Ortodontia, São Paulo, v. 25, n. 1 , p. 22-33, jan./mar. 2002

38. SILVA FILHO, O. G. et al. Hábitos de sucção e má-oclusão: epidemiologia na dentadura decídua. Rev. Clin. Ortodon. Dental Press, Maringá, v. 2, n. 5, p. 57-74, out./nov. 2003.

39. VAN DER LAAN, Thomas. A importância da amamentação no desenvolvimento facial infantil. Pro-Fono: Rev Atual. Científ. Barueri, v. 7, n. 1, p. 20-27, 1997. 